\title{
On energy-saving control during the power plant production process and its applications
}

\author{
Song Zhao ${ }^{1, \text { a }}$ \\ ${ }^{1}$ North China Electric Power University,Beijing 102206, China \\ anbzsongge@163.com
}

\begin{abstract}
Keywords: power plant production; energy-saving control; technical application
Abstract. Faced with the threat of environmental pollution and energy consumption, China has put forward the sustainable development policy, and encouraged all sectors and industries to realize energy-saving production. As important energy supply units, power plants should also actively explore an energy-saving production path. Based on such an understanding, this paper analyzes the production process of power plants, and discusses energy-saving control techniques of power plants and their applications at an attempt to provide references for people interested into the issue.
\end{abstract}

\section{Introduction}

As energy supply units, power plants are also huge energy-consumption units. To realize energy-saving control of the power plant production process can help reduce energy consumption of power plants and improve their power generation capacity. It is conducive to sustainable development of the national economy. Therefore, to electric enterprises, their primary task is to achieve efficient energy-saving control. Currently speaking, the automatic control technique and the high-voltage motor speed frequency control technique both belong to energy-saving control techniques. They are worth scholars’ further analysis and research.

\section{Analysis of the power plant production process}

The power plant production process is actually a process of transforming chemical energy, thermal energy and mechanical energy into the electric energy. Though power plants might differ in terms of capacity and form, generators are required to transform other forms of energy into the electric energy. Take condensing coal-fired power plants for example. Power plants of the kind consist of the combustion system, the steam-water system and the electric system. Through the combustion system, the coal dust can be sent into the boiler furnace for combustion. Then, the heat is transferred to the water in the steam-water system through the water-cooled furnace wall. The water in the steam-water system is transformed into the water vapor through heating and boiling. After that, the turbine propels the blade to form mechanical energy. If the turbine rotates around the generator rotor, the electric power can be generated [1]. Generators are a part of the electric system of power plants. Part of the electric power generated is distributed to draught fans, water pumps and other electric equipment. The other part is output through the high-voltage distribution device and the booster station.

\section{Research into energy-saving control techniques during the power plant production process}

From the perspective of the power plant production process, the generation of the electric power calls for coordination of the fire coal system, the steam-water system, the electric system and other auxiliary production systems. Therefore, in order to realize efficient energy-saving control during the power plant production process, various production system should well cooperate with each other so as to improve the electric power production efficiency and reduce the production waste. The use of energy-saving control techniques can contribute to the coordinated operation of the whole system and the main system for power plants and efficiently finish the electric energy production tasks. 


\subsection{Analysis of the automatic control technique}

The automatic control technique combines various scientific techniques, including network communication techniques, computer techniques and electromechanical integration techniques. Therefore, it has multiple control functions, which can use multiple control units to realize green production of the power plant system. On the one hand, it can improve the generation efficiency of power plants; on the other hand, it can reduce energy consumption and environmental pollution of the power plant production. Therefore, to introduce the automatic control technique to the power plant production can achieve energy-saving control during the power plant production process. First, the automatic control technique can be employed to monitor operating situations of various kinds of energy-saving equipment, and achieve real-time adjustment of equipment of various types. Thus, the automatic control technique can maintain different system equipment in a favorable operation status. Second, the automatic control technique can achieve real-time sharing of the power plant production information of all kinds. In this way, management personnel can obtain efficient information for their management of the power plant production process, and improve the power generation efficiency and quality. Third, the automatic technique can speed up the actualization speed of various production parameters, and upgrade the system's data processing capability, Besides, applications of the automatic control technique during the power control system can maintain the steady operation of the system [2]. The acquisition of accurate system and equipment control data can promote efficient control of different systems and equipment. Based on that, the objective of the energy-saving production can be made real.

\subsection{Analysis of the motor speed frequency control technique}

During the power plant generation process, different kinds of equipment like draught fans and water bumps are propelled by motors. To reduce the operation energy consumption of different kinds of system equipment can realize energy-saving control of the power plant production process. In principle, the operation of asynchronous motors is related to number of pole-pairs, the slip ratio, the power frequency, the rotation speed and other parameters of motors. P, s, f and n stand for the number of pole-pairs, the slip ratio, the power frequency and the rotation speed, respectively, in the formula, $\mathrm{n}=60(1-\mathrm{s}) / \mathrm{p}$. The high-voltage motor speed frequency control technique can adjust and control the motor speed. However, the relationship between the power frequency and the motor rotation speed is a linear one. Therefore, the motor rotation speed will not be influenced by other factors. Even if the system is influenced by the draught fan chock or the excitation slip frequency, it will not result in loss of the motor power. Therefore, the high-voltage motor speed frequency control technique can efficiently improve the motor energy-saving effect [3]. However, the use of traditional flow regulation or the electromagnetic slip energy-saving regulation might put motors to operate at a high speed, making choking and speed adjustment invalid. Compared with the other speed adjustment and control techniques, the high-voltage motor speed frequency control technique can ensure normal operation of motors. Besides, it is highly reliable, thus obtaining wide applications during the power plant production process.

\section{Discussion of applications of energy-saving control techniques to the power plant production process}

4.1 Applications of the automatic control technique to the energy-saving production process of power plants

Applications of the automatic control technique during the power plant production process call for the construction of an automatic control system. To be specific, two sets of CRT stations are adopted for the construction of the central control system. Then, the system control unit is used for man-machine interaction, information browsing and completion of real-time monitoring and information collection of the power plant equipment. Functions of the central control system and the information module can be made use of to help realize remote control and data signaling. Based on the operation platform software of WIN, the system realizes its upper computer so as to finish data statistics, parameter adjustment and site control of power plant equipment. The industrial personal 
computer and the PLC chip can help realize data collection, analysis and command implementation. After designing the above parts, the author builds the automatic control system for power plants. Equip the instrument control device in every production workshop. Use computer techniques and communication bus techniques for collection and control management of equipment data. In this way, equipment operation efficiency and quality can be improved. While using the automatic control system for the power plant production process management, the author thinks the site key control equipment can be used to control the operation screen so that the production site can be put under real-time monitoring [4]. According to information parameters, including switch-on and switch-off, the valve status, the technical parameters and the environmental test of the site, the system can be used for parameter entering and modification. In this way, the equipment operation can be efficiently controlled and the system's energy-saving production can be realized.

4.2 Applications of the motor speed frequency control technique to the energy-saving power plant production

During the power plant production process, the application of the high-voltage motor speed frequency control technique calls for the following preparations. First, the high-voltage motor speed frequency control equipment should adapt to voltage fluctuations of motors so that full-load output of motors within the specific voltage fluctuation range can be achieved. Under general conditions, the voltage fluctuation range is $-20 \% \sim+15 \%$. It should be noted that, under the condition of separation and merge of power plant equipment for protection, switchover of commonly-used power and launch of large-scale motors, the voltage value will be lower than the normal value. Considering the problem, it is also necessary to avoid frequent operations of the equipment switch-on and switch-off; otherwise, voltage will fluctuate dramatically. Second, when the high-voltage motor speed frequent control technique is adopted for equipment speed adjustment, the motor rotation speed should be determined according to practical situations. Generally speaking, draught fans and water pumps can achieve favorable energy-saving effects while reaching $60 \%$ of the rated flow value. Thus, the equipment speed adjustment should be based on practical situations instead of blindly attempting to reduce the rated flow of equipment [5]. Besides, the application of the high-voltage motor speed frequency control technique for equipment management requires that the output current harmonics of power plants should not be too huge for the fear of system damage, inaccurate measurement and poor control performance. To the end, the output current of equipment should be controlled within certain range to better control the output current harmonics of the high-voltage motor speed frequency control equipment.

\section{Conclusions}

All in all, with the increasing prominence of the issue of energy shortage, power plants have to conduct energy-saving control of the production process so as to improve the utilization rate of the petroleum resources and reduce the pollution of electric power to surroundings. To apply the automatic control technique and the high-voltage motor speed frequency control technique to energy-saving production and control of multiple systems of power plants can help improve the operation efficiency of different kinds of system equipment and the production efficient of electric energy. Therefore, the author believes that research into the issue of energy-saving control during the power plant production process can provide useful references for relevant fields.

\section{References}

[1]Liu X J \& Kong X B. Present situation and prospect of model predictive control application in complex power industrial process[J]. Proceedings of the CSEE, 2013, 05: 79-85+14.

[2]Miao L. A preliminary research into exhaust gas temperature control of the power station boiler[J]. Technology Innovation and Application, 2013, 10:6-7. 
[3]Zhang J M, Zhang $\mathrm{CH} \mathrm{L,} \mathrm{Wu} \mathrm{G} \mathrm{ZH,} \mathrm{et} \mathrm{al.} \mathrm{Design} \mathrm{and} \mathrm{development} \mathrm{of} \mathrm{the} \mathrm{data} \mathrm{acquisition} \mathrm{and}$ analysis system for the provincial combined heat and power plants[J]. Automation of Electric Power Systems, 2011, 06: 71-75.

[4]Guo ZH J. Discussion on the application of energy saving technology in thermal power plant construction[J]. Shanghai Energy Conservation, 2011, 04: 29-32.

[5]Jiang H Y, Tan ZH F, Hu Q H, et al. Action analysis of nominal power plants on energy saving and emission controlling of power industry[J]. Electric power, 2010, 06:37-40. 